\title{
Exploring Adjectives in Health Advertorials
}

\author{
Eva Tuckyta Sari Sujatna, Susi Yuliawati
}

\author{
Department of Linguistics, Universitas Padjadjaran, Indonesia
}

\begin{abstract}
This paper studies the types and functions of English adjectives in health advertorial of the Health magazine. From five health advertorials, the present research discovered adjectives that operated in two functions, namely attributive and predicative. The texts in the health advertorials had more attributive adjective than predicative adjective. The number of the attributive adjective was 98 while the predicative one was 31. The dominant type found in the attributive adjective was nongradable adjective (52 out of 98 data) while in the predicative adjectives was gradable adjective (19 out of 31 data). Furthermore, from the total adjectives of 129 data, the present writers found 96 different adjectives that are classified into three categories, i.e. scalar, extreme, and limit. In both attributive and predicative adjectives, limit adjective was most frequent adjective. Besides, extreme adjective was discovered to be the least frequent category of adjective in the attributive adjective as well as the predicative adjective. It suggested that the use of attributive and predicative adjectives in terms of limit, scalar and extreme category tends to show the similar pattern. Additionally it is important to note that there are three adjectives that function both as attributive and predicative adjectives, i.e. BUSY, EASY, and IMPORTANT.
\end{abstract}

Keywords-adjective, attributive, extreme, limit, predicative, scalar.

\section{INTRODUCTION}

Linguistics as a study of language cannot stand alone as a science. In their development, research on linguistics has interacted with other disciplines. For that reason, linguistics can collaborate with the study of tourism, communication, teaching, health sciences, media, etc. the example of linguistic research collaborating with health science was conducted by Pamungkas and Abdulah (2017) that studied the linguistics-based product naming methods of some over the counter (OTC) medicines in Indonesia and their impacts to companies and consumers. The other example is the combination of linguistics and media done by Sujatna et al. (2018) who examined thematic progression of higher education in English and Bahasa Indonesia advertorials. Because linguistics is possible to collaborate with other sciences, the present paper is the combination of linguistics and media, in particular advertorials derived from magazine.
There has been some research on adjectives such as from Bolinger (1967), Vandelanotte (2002), and Giegerich (2005). Bolinger (1967) introduced two functions of adjectives in English, viz. predication and attribution in his paper entitled Adjectives in English: Attribution and Predication. Vandelanotte (2002) discussed prenominal adjectives in English in his paper entitled Prenominal Adjectives in English: Structures and Ordering. Giegerich (2005) studied English adjectivenoun constructions involving associative adjectives in his paper entitled Associative adjectives in English and the lexicon-syntax interface. This previous research on adjective used English language as the object of the study, but did not examine adjective in particular type of text.

The description of adjective is generally based on its function, type, and meaning such as, describing feeling, nationalities, qualities, size, value, shape, and color. However, identifying adjective is sometimes problematic in some languages although recent linguistic studies claimed that adjective is a word class that exists in all languages (Ollennu, 2017). In terms of type, Paradis (2001) argued that adjective consisted of three categories, i.e. scalar adjective, extreme adjective and limit adjective. In this research, the present writers investigate adjective based on its type and function in English texts derived from health advertorials.

The term advertorial is formed from two English words, viz. advertisement and editorial. Advertorial is defined as an advertisement text that is written in an editorial way. For this research, the data are five advertorials derived from Health magazine accessed through https://www.health.com/. The texts in the advertorials have many topics such as health, news, food, weight loss, beauty, fitness, and life issues. This study uses the texts from advertorials of the Health magazine, which is published online, as the data. This is in line with Robinson, et al. (2007) who studied the language of internet advertising which tittle is "Internet advertising effectiveness: The effect of design on click-through rates for banner ads".

Like editorial, an advertorial text is usually begun with fact or information that is written in a positive way or based on research findings. Since it is an advertisement text, it also promotes something, either products or services, which is written at the end of the text. An advertorial text usually presents information that is 
supported by certain research findings with the aim to convince readers and to finally make them interested in buying the products or services offered in the advertorial.

This paper investigates English adjectives used in the advertorial texts, particularly in health advertorials. From the data, the present writers identify and analyze the types and functions of adjectives found in each type of health advertorial.

\section{METHOD}

This research is a preliminary research on adjective found in advertorial texts. The data were collected from an online magazine, Health. The magazine has many rubrics and one of them is health advertorial. This study used seven health advertorials from the magazine as the data. The first step of the research was identifying adjectives in the texts and analyzing them based on their function, i.e. attribution or predication. The second step was describing adjectives based on the category of gradable or nongradable. The last step was describing the meaning of every adjective based on its context of use in the clause.

The method applied in this research is descriptive analysis meaning that every data are described based on indicators that are designed. The research design is qualitative, but some data are quantified simply to show the frequency of adjectives so that the pattern of uses of adjectives, based on their type and function, in the advertorial texts can be presented clearly.

The data were collected from five health advertorials in Health magazine, accessed through https://www.health.com/. The five titles of the advertorials are A Solution to Overcome Stress in Our Immune System, Mom is Warning Parents after Finding Metal in Her Daughter's Vitamins, Can Emergen-C Actually Prevent a Cold?, 9 Things to Know Before Buying Another Supplement, and 5 Healthy Foods That are Keeping You Up at Night.

\section{ADVERTORIAL IN MAGAZINE}

In 1989 Stout et al. defined that magazine advertising supplements, commonly referred to as "advertorials," are one of the fastest growing media trends in the industry today. Although the opinion was stated almost thirty years ago, advertorial apparently remains to be one of the popular medias chosen to promote products or services and to communicate with readers as future potential buyers. Therefore, advertorial can be defined as a media of communication between writers and readers.

Communication is a process of sharing through verbal and nonverbal behavior as Levine and Edelman (in Mulyana, 2012) and Condon and Yousef (in Mulyana, 2012) argued that the cultures of speakers or writers influence the way they communicate,

"Communication involves expectation, perception,

choice, action, and interpretation. Every time you communicate with someone, there is no doubt that he or she comes from a cultural environment. This means that what he or she says and the way he or she behaves is influenced by his or her culture, although this doesn't mean that all members of the culture behave in exactly the same way."

The cultural background of a writer will influence the text, which is regarded as a media of communication between writers and readers. In other words, different writers with different cultures will have different ways of expressions in their writings.

Advertorials are designed as informative as possible, in line with material feature; they typically have longer copy (Cameron \& Ju-Pak, 2000). Kim, Pasadeos, and Barban (2001) describe that an advertorial is "a print advertisement disguised as editorial material". The argumentation is in line with Brown and Waltzer (2004) who argued that advertorial is an important tool used by organized interests to create an advantageous public opinion climate regarding controversial is sues.

\section{ADJECTIVES: TYPES AND FUNCTION}

Adjective is one of the word classes that is restricted to attributive and predicative use (Quirk et al., 1992). As an attributive use, adjective is used to describe noun, for example the adjective OLD in the phrase the old woman. The adjective OLD attributes to the noun WOMAN. Besides as an attributive adjective, the adjective OLD can also be used as predication, for example in the clause She is old. The study on adjectives is not limited only by identifying adjectives on the basis of attribution or predication, but also possible to be done by investigating the types of attributive and predicative adjectives in the level of clause, sentence, or even text. As an attribution, adjective gives more description or even gives readers more illustration of the things that the adjectives modify because they function to narrow the meaning of nouns (Stubbs, 2002 and Quirk et al., 1992). As a predication, adjective modifies the subject of a clause. It means that adjectives used in advertorial texts allow writers to give more illustration or description about products or services that are offered to readers. For that reason, the present writers examine the adjectives by identifying their functions and types used in advertorials.

Adjective is one of the open word categories. As an open category (besides verb, noun, and adverb), adjective is the largest word class after nouns and verbs (Sujatna, 2014). Adjective is also a word class that is still possible to accept affix in order to change its meaning or its category, for example, the adjective RED + -ish becomes REDDISH 'slightly red'. By adding suffix -ish, the meaning of the word RED changes into slightly red. Adjective is also used to denote personality and appearance (Stubbs, 2002). In addition, Baker (2004) and 
Sujatna (2014) argued that adjective is usually used to describe people, things, places, states or properties, which are typically medium-length states of affairs.

In terms of the type, adjective is categorized into gradable and non-gradable adjective. Gradable adjective is the adjective that shows degrees. In English the adjective COLD is possible to change into COLDER or COLDEST, or it can be modified by adding a degree word such as VERY as in it is very cold. The gradability of adjective is classified into three different types (Paradis, 2001), which are 1) scalar adjectives, such as LONG, GOOD, NASTY; 2) extreme adjectives, such as TERRIBLE, BRILLIANT, DISASTROUS; and 3) limit adjectives, such as DEAD, TRUE, IDENTICAL.

Scalar adjective exhibits all typical features of antonyms as defined by Cruse (in Paradis, 2001). They are fully gradable, i.e. they occur in the comparative and the superlative. The members of the scalar adjective denote some variable property such as length, speed, weight, merit, personality, etc. According to Paradis, (2001: 5),
"Extreme adjectives combine with reinforcing totality modifiers (absolutely terrible, totally brilliant, utterly disastrous). Like scalar adjectives, extreme adjectives too are antonymic and conceptualized according to a scale. Extreme adjectives differ from scalar adjectives in that they do not represent a range on a scale. They represent the ultimate point of a scale. People's opinions diverge as to the comparability of extreme adjectives".

Furthermore, Paradis (2001) argued, "Limit adjectives combine with totality modifiers (completely dead, absolutely true, almost identical). Limit adjectives are logically different from scalar and extreme adjectives in that they are not associated with a scale but conceptualized in terms of 'either-or'. Limit adjectives are complementary. They do not occur in the comparative or the superlative (?deader, ?deadest)".

Besides the functions of adjective as attribution or predication and the types of adjective as gradable adjective-scalar, extreme and limit adjectives -or nongradable adjective, adjective also has several categories of meaning (Dixon \& Aikhenvald, 2004). It is classified into seven major types, viz. dimension, age, value, color, physical property, human, and speed.

\section{RESULTS AND DISCUSSION}

The discussion about adjective in health advertorial texts is divided into two sections. First, the discussion is based on the function of adjective, which are attribution and predication. Second, the investigation is based on the type of adjective, which is gradable and non-gradable adjective.

\subsection{Attributive and Predicative Adjectives}

From the data collected, the total number of adjectives that we discovered is 129 , which are classified into attributive adjectives and predicative adjectives. There are more attributive adjectives than predicative adjectives in the texts. The attributive adjectives are 98 data while the predicative adjectives are 31 data (see Fig.1)

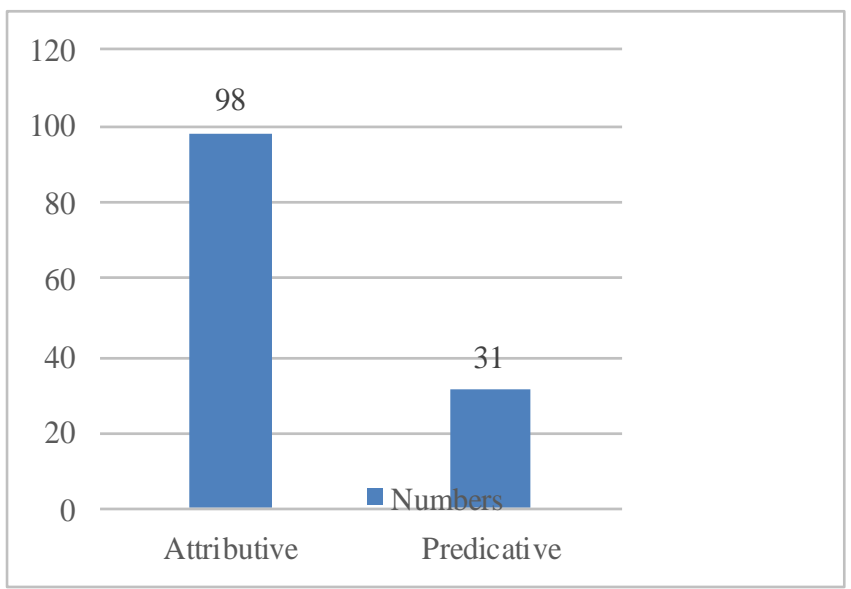

Fig.1: The Attributive and Predicative Adjectives in Five Health Advertorials

The attributive adjectives as presented in Fig. 1 are the adjectives that combine with other category as noun phrases.

(1) "Sometimes in medicine there is a lot of uncertaintythere have been some really good programmes, such as Brain Doctors and Great Ormond Street, which showed a group of doctors actually discussing whether someone should be treated and how."

(2) "Symptoms of mild to moderate dehydration include dry mouth, tiredness, headache, muscle tiredness and dizziness."

Data (1) and (2) above are the example of attributive adjectives found in the advertorial texts. The attributive adjectives are GOOD and DRY. The adjective GOOD is attributive adjective because it modifies the noun PROGRAMMES in the noun phrase some really good programmes. Like the adjective GOOD, the adjective DRY is attributive that modifies the noun MOUTH in the noun phrase dry mouth. Therefore, the word DRY is attributive adjective.

Unlike attributive adjectives, predicative adjectives are found only 31 in the data (see Fig. 1). They are categorized as predicative because they function as the complement of the clause, which modifies subject, as described in the following data.

(3) Yet by the time you actually feel thirsty, your body is already in a mild state of dehydration.

Data (3) shows that adjective THIRSTY complements to pronoun YOU, which is the subject of the clause. Thus, the adjective THIRSTY is a subject complement which is identified as a predicative. 


\subsection{Gradable and Non-gradable Adjectives}

Both gradable and non-gradable adjectives are found in the health advertorials. Gradable adjectives, which are defined as the adjectives that have different degrees, were found in the health advertorials as attributive and predicative adjectives. Fig. 2 present the classification of adjectives based on the function (attributive and predicative) and gradability (gradable and non-gradable) found in the data.

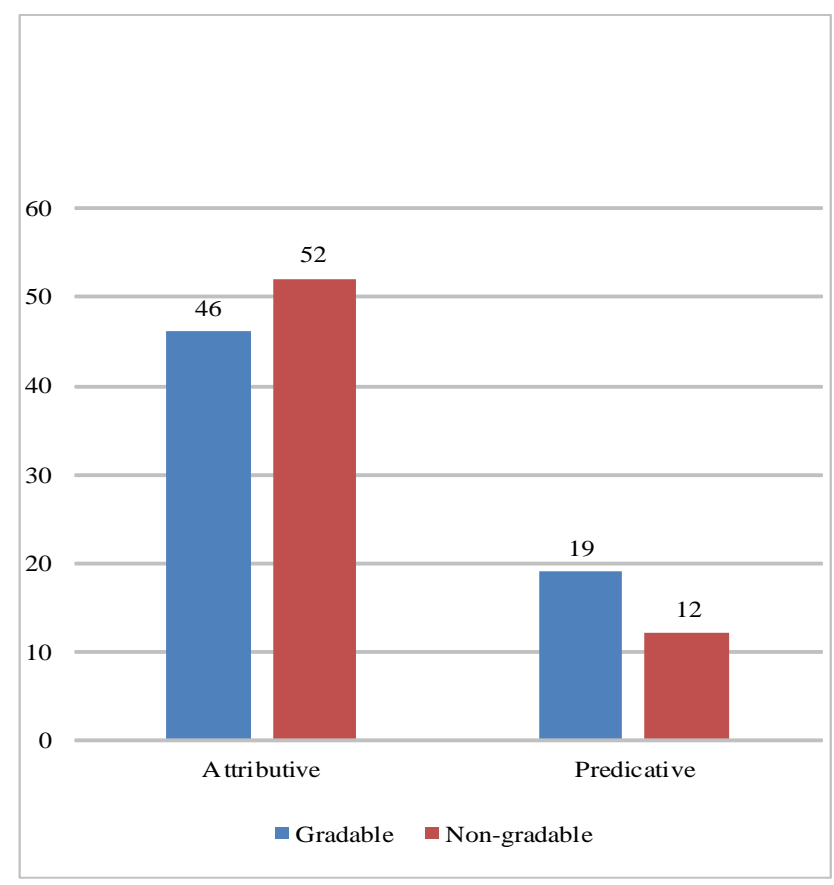

Fig. 2: Gradable and Non-Gradable Adjectives in Five Advertorials

Fig. 2 displays that non-gradable is dominant in attributive adjective, but it is not in the predicative adjectives. The data below are the illustration of gradable and non-gradable attributive-data (4) and (5)-and predicative adjectives-data (6) and (7).

(4) "But that's rare and often it looks as though there is a clear route through every illness, but frequently there isn 't."

(5) "Also, if we drink a lot of alcoholic beverages such as beer, we're more likely to produce gas," he says.

From the two data above, the adjective CLEAR in data (4) and the adjective ALCOHOLIC in (5) are categorized as attributive. Data (4) is gradable attributive adjective because the word CLEAR can be changed into comparative and superlative. Moreover, it can be preceded by a degree word such as VERY as described in the (4)c.

Unlike the adjective CLEAR in data (4), the adjective ALCOHOLIC is unable to be changed into comparative and superlative adjective and also cannot be preceded by the degree word VERY since the adjective ALCOHOLIC is categorized into non-gradable attributive adjective. The gradable attributive adjectives of CLEAR are:
(4)a ... there is a clearer route...
(4)b ... there is the clearest route ....
(4)c ... there is a very clear route ...

The non-gradable attributive adjectives of ALCOHOLIC are:

*(5)a It is more alcoholic beverage....

*(5)b It is the most alcoholic beverage ....

$*(5) \mathrm{c}$ It is very alcoholic....

Data (4)a, b, and c describe that the gradable adjectives CLEAR can be formed as comparative in (4)a, and superlative in (4)b, and combine with the degree word VERY in data (4)c. Data (5)a, b, and c demonstrate that the gradable attributive adjective ALCHOHOLIC cannot be changed into comparative and superlative forms of the adjective ALCHOHOLIC while (5)c shows that the adjective ALCHOHOLIC cannot occur with the degree word VERY.

(6) “..., but if it's dark, that's a sign of dehydration."

(7) "If your urine is pale to light yellow this is normal,...."

The two data above describe the predicative adjective dark and normal. Both adjectives are categorized into predicative but they have a little bit differences: dark is categorized into gradable predicative adjective and normal is non-gradable predicative adjective. The data (6) is categorized into gradable predicative adjective since it could be changed into comparative, superlative, and could be preceded by degree word very as described in (6) a, b, and $c$ while the predicative adjective normal could not, as described in (7) a, b, and c.

The gradable predicative adjective dark:

(6)a The color is darker than before.

(6)b It is the darkest color I have ever seen.

(6)c The color is very dark.

The non-gradable predicative adjective normal:

*(7)a This more normal than others.

*(7)b This is the most normal...

*(7)c This is very normal ....

It is reported, there are 129 data containing adjectives in the five health advertorials. From 129 data, it is found 96 different adjectives; they have different number since there are similar adjective found more than once in the data. Relating to the data analyzed, it is found various types of adjectives in the data as described in Table 1 and Table 2 .

Table 1. The Attributive Adjective Based on Its Type in Five Advertorials

\begin{tabular}{|c|c|c|c|c|c|}
\hline \multicolumn{5}{|c|}{ Attributive } \\
\hline \multicolumn{3}{|c|}{ Gradable } & \multicolumn{2}{c|}{ Non-Gradable } \\
\hline \multicolumn{3}{|c|}{ Scalar } & \multicolumn{2}{c|}{ Extreme } & \multicolumn{2}{c|}{ Limit } \\
\hline $\begin{array}{l}\text { No. of } \\
\text { data }\end{array}$ & $\begin{array}{l}\text { No. of } \\
\text { adj. }\end{array}$ & $\begin{array}{l}\text { No. of } \\
\text { data }\end{array}$ & $\begin{array}{l}\text { No. of } \\
\text { adj. }\end{array}$ & $\begin{array}{l}\text { No. of } \\
\text { data }\end{array}$ & $\begin{array}{l}\text { No. of } \\
\text { adj. }\end{array}$ \\
\hline 40 & 26 & 6 & 2 & 52 & 39 \\
\hline
\end{tabular}


Relating to the function of the adjectives, Table 1 and Table 2 demonstrate that non-gradable attributive adjective in the type of limit is the most dominant kind of adjectives found in the data.

Table 2. The Predicative Adjective Based on Its Type in Five Advertorials

\begin{tabular}{|c|c|c|c|c|c|}
\hline \multicolumn{5}{|c|}{ Predicative } \\
\hline \multicolumn{3}{|c|}{ Gradable } & \multicolumn{2}{c|}{ Non-Gradable } \\
\hline $\begin{array}{l}\text { No. of } \\
\text { data }\end{array}$ & $\begin{array}{l}\text { No. of } \\
\text { adj. }\end{array}$ & $\begin{array}{l}\text { No. of } \\
\text { data }\end{array}$ & $\begin{array}{l}\text { No. of } \\
\text { adj. }\end{array}$ & $\begin{array}{l}\text { No. of } \\
\text { data }\end{array}$ & $\begin{array}{l}\text { No. of } \\
\text { adj. }\end{array}$ \\
\hline 7 & 7 & 12 & 10 & 12 & 12 \\
\hline
\end{tabular}

\subsubsection{Gradable and Non-Gradable Attributive Adjectives}

From the data described in Table 1 and Table 2, the highest number of adjective is limit non-gradable attributive adjectives. It has 52 four data with 39 different types of adjectives. The 39 types of adjectives are abdominal, achievable, active, adequate, adverse, alcoholic, average, central, coeliac, digestive, electrical, false, frequent, future, general, gentle, great, harmful, honest, hormonal, major, medical, menstrual, middleaged, moderate, oversensitive, perfect, persistent, real, recent, regular, right, scented, serious, severe, social, unhealthy, uninterrupted, and wrong. The following is the examples of the data:

(8) If constipation is the problem, psyllium husks act as a gentle laxative and work well with slippery elm."

(9) Regular exercise is thought to help maintain your digestive system.

Data (8) and (9) above are the examples of limit as the types of non-gradable attributive adjectives.

The second highest number of adjectives found in the data is scalar. Scalar adjective is one of the gradable attributive adjective types. Table 1 describes 40 data found with 26 different types of adjectives. The 26 scalar adjectives are busy, clear, clever, common, dry, easy, emotional, free, good, healthy, high, hot, immediate, important, late, light, mild, older, quick, shorter, simple, small, specific, unable, uncomfortable, and worth. The following is the example of the data:

(10) To check if you are drinking enough water throughout the day, there are two simple tests you can do-both backed up by medical insight.

(11) We love real-life medical shows like Channel 4's 24 Hours in A\&E and One Born Every Minute - but could their clever editing be giving us the wrong impression about how the NHS actually works?

Data (10) and (11) describe the examples of scalar as one of the types of gradable attributive adjectives. The other type of adjectives in gradable attributive is extreme adjectives. The number of extreme attributive adjectives found in the data is in the third position after limit and scalar. There are only six extreme gradable attributive adjectives in two different words (see Table 1). The two words are bloated and chronic as described in the following data.

(12) "A bloated stomach can be a symptom of some specific food sensitivities, such as lactose intolerance," Dr. Hicks explains.

(13) "Chronic bloating in women is one of the key symptoms of ovarian cancer," says Dr. Hicks.

The two data above have two different extreme adjectives as gradable attributive adjectives. They are extreme adjectives because they cannot not be change into comparative and superlative adjectives.

\subsubsection{Gradable and Non-Gradable Predicative Adjectives}

Table 2 dis plays the number of gradable and non-gradable predicative adjectives that we discovered in the data. Similar to non-gradable attributive adjectives that has been discussed previously, the limit adjective is the dominant number found in the data analyzed. There are 12 data found in 12 different words. The 12 words are able, common, fizzy, ideal, light-yellow, impossible, incorrect, normal, odd, optimal, unsustainable, and worth. From the data collected, the non-gradable predicative adjectives are described in the following data:

(14) 'I can't bear dramas such as Casualty and Holby City, because they can be medically incorrect.

(15) "It might sound odd, but I think it is really important for medical professionals within the NHS to see each other's work, and reality shows help with this.

Both of the data show that the adjectives incorrect and odd are limit adjectives, as they cannot be changed into comparative and superlative adjectives.

Similar to attributive adjectives, the predicative adjectives also have gradable predicative adjectives. In the gradable predicative adjectives, the extreme as one of the gradable types is the dominant. It has 12 number of data with 10 different adjectives. The 10 adjectives are anxious, desperate, ill, miserable, pale, rare, ridiculous, shy, stressed, and thirsty. From the data collected, the non-gradable predicative adjectives are described in the following data:

(16) The more people who know this the better. I've had a call out for a toothache before, which is ridiculous.

(17) So if, for example, you're fairly shy, you'll drink at a party to boost your confidence.

The adjectives ridiculous and shy are categorized into extreme adjectives since they cannot be changed into comparative and superlative adjectives. The last type of predicative adjective is scalar. There are 7scalar predicative adjectives in the data in 7 different words. They are busy, dark, easy, important, sensitive, unhappy, and vague. Here are the examples of the data. 
(18) Symptoms of ovarian cancer are vague, though there are some common signs to look out for.

(19) "It might sound odd, but I think it is really important for medical professionals within the NHS to see each other's work, and reality shows help with this.

(20) "For instance, some women are more sensitive than others to fluctuations in hormones that lead to bloating during their menstrual cycle."

Data (18)-(20) describe that the adjectives vague, odd, and sensitive function as predicative. They are categorized into scalar adjectives since they have comparative and superlative adjectives.

\section{CONCLUSION}

From the discussion of adjectives in five health advertorials, the present writers discovered attributive and predicative adjectives. From 129 data, the number of attributive adjectives is 98 while the predicative adjectives are 31 . It suggests that attributive adjective is dominantly used in the five texts of health advertorials.

Among the attributive adjectives, which consist of gradable and non-gradable adjectives, the highest number of adjectives is limit non-gradable adjectives, i.e. 52 data, followed by scalar gradable adjective, i.e. 40 data, and extreme gradable adjective, i.e. 6 data. The predicative adjectives are also classified into gradable and nongradable in which the limit and extreme adjectives show the same number, i.e. 12 data. The lowest number predicative adjective is scalar adjective, i.e. 7 data.

From the 98 different adjectives found in the 5 health advertorials, the present writers found three similar words found in both scalar attributive and predicative adjectives. They are BUSY, EASY, and IMPORTANT.

\section{REFERENCES}

[1] Baker, Mark C. (2004). Lexical Categories: Verbs, Nouns, and Adjectives. Cambridge: Cambridge University Press.

[2] Bolinger, Dwight. (1967). Adjectives in English: Attribution and Predication. Lingua. 18. 1-34. 10.1016/0024-3841(67)90018-6.

[3] Cameron, G. T., \& Ju-Pak, K.-H. (2000). Information Pollution?: Labeling and Format of Advertorials. Newspaper Research Journal, 21(1), 65-76. doi:10.1177/073953290002100106

[4] Dixon, R. M. W., \& Alexandra Aikhenvald. (eds.) (2004). Adjective Classes. A Cross-Linguistic Typology. Oxford. Oxford University Press

[5] Giegerich, Heinz J. (2005). Associative adjectives in English and the lexicon-syntax interface. Journal of Linguistics - J LINGUIST. 41. doi: 10.1017/S0022226705003440.

[6] Kim, Bon-Hyun, Yorgo Pasadeos, Arnold Barban. (2001). On the deceptive effectiveness of labeled and unlabeled advertorial formats. Mass Communication and Society. 4(3): 265-281.

[7] Mulyana, Deddy. (2012). Cultures and Communication. Bandung: PT. Remaja Rosdakarya.

[8] Ollennu, Yvonne Akwele Amankwaa. (2017). On Predication of Adjectives in Ga. International Journal of Linguistics. 9(2), 70-91. doi: 10.5296/ijl.v9i2.11067

[9] Pamungkas, Kasno \& Rizky Abdulah. (2017). Linguistics-Based Pharmaceutical Product Naming Methods: Asian Journal of Pharmaceutical and Clinical Research. 10.108. doi: 10.22159/ajpcr.2017.v10s2.19512.

[10] Paradis, Carita. (2001). Adjectives and boundedness. Cognitive Linguistics 12(1): 47-65

[11] Quirk, Randolph. Sidney Greenbaum, Geoffrey Leech, Jan Svartvik. (1992). A Comprehensive English Grammar. London: Longman.

[12] Robinson, Helen, Anna Wysocka, Chris Hand. (2007). Internet advertising effectiveness. International Journal of Advertising, 26(4), 527541. doi:10.1080/02650487.2007.11073031

[13] Stout, Patricia. A., Garry B. Wilcox, Lorrie S. Greer. (1989). Trends in Magazine Advertorial Use. Journalism Quarterly, 66(4), 960-964. doi:10.1177/107769908906600430

[14] Stubbs, Michael. (2002). Words and Phrases: Corpus Studies of Lexical Semantics. London: Blackwell

[15] Sujatna, Eva Tuckyta Sari. (2014). Understanding English Syntax. Sumedang: Unpad Press.

[16] Sujatna, Eva Tuckyta Sari, Kasno Pamungkas, Heriyanto. (2018). Thematic Progression of Higher Education Advertorials: A Case Study in English and Bahasa Indonesia. Advances in Social Sciences Research Journal. 5. 10.14738/ass rj.58.4655.

[17] Vandelanotte, Lieven. (2002). Prenominal Adjectives in English: Structures and Ordering. Folia Linguistica, 36(3-4). doi:10.1515/flin.2002.36.3-4.219 